\title{
Examining Psychosocial Pathways Underlying Gratitude Interventions: A Randomized Controlled Trial
}

\author{
Brenda H. O'Connell ${ }^{1}$ - Deirdre O'Shea ${ }^{2} \cdot$ Stephen Gallagher $^{3}$
}

Published online: 20 October 2017

(C) Springer Science+Business Media B.V. 2017

\begin{abstract}
Despite their unprecedented popularity, the psychological mechanisms through which gratitude journals operate are poorly understood. Also the use of gratitude journaling to enhance social relationships has been neglected in past research, despite the importance of healthy relationships for people's happiness. This randomized controlled study examined the effect of (a) a traditional gratitude journal (fostering gratitude for daily life), and (b) an interpersonal gratitude journal (fostering gratitude for one's existing social relationships), versus (c) an active control journal, on life satisfaction. Ninety-one participants were randomized to one of three conditions with 2-week and 1-month follow-ups. The traditional gratitude intervention (vs. control) showed improvements in friendship at immediate post-test and 1-month follow-up, and these effects were accounted for by changes in gratitude over time. Additionally, the traditional gratitude intervention (vs. control) predicted enhanced life satisfaction at follow-up, and this was serially mediated by 6 week changes in gratitude and perceived friendship quality. No such differences over time were observed between the interpersonal gratitude intervention and either the control intervention or the traditional gratitude intervention. Actively appreciating things in daily
\end{abstract}

Electronic supplementary material The online version of this article (doi:10.1007/s10902-017-9931-5) contains supplementary material, which is available to authorized users.

Brenda H. O'Connell

brenda.h.oconnell@mu.ie

Deirdre O'Shea

deirdre.oshea@ul.ie

Stephen Gallagher

stephen.gallagher@ul.ie

1 Department of Psychology, National University of Ireland Maynooth, Maynooth, Kildare, Ireland

2 Department of Personnel and Employment Relations, Kemmy Business School, University of Limerick, Limerick, Ireland

3 Centre for Social Issues Research, Study of Anxiety, Stress and Health Lab, Health Research Institute, Department of Psychology, University of Limerick, Limerick, Ireland 
life appears to be effective in enhancing the quality of people's social relationships, and producing sustained improvements in subjective wellbeing.

Keywords Gratitude interventions · Randomized controlled trial · Social relationships $\cdot$ Life satisfaction $\cdot$ Happiness

\section{Introduction}

The study of gratitude has recently experienced rapid growth in scientific literature. Gratitude has been depicted as "the willingness to recognize the unearned increments of value in one's experience" (Bertocci and Millard 1963, p. 389) and has been discussed and conceptualized as an "emotion, an attitude, a moral virtue, a habit, a personality trait, or a coping response" (Emmons and McCullough 2003, p. 337). Cross-sectional and longitudinal evidence shows that gratitude is positively linked to subjective wellbeing and life satisfaction (Emmons and Shelton 2002; Watkins et al. 2003), positive social relationships (Algoe 2012; Algoe et al. 2008) and physical health (Emmons and McCullough 2003). In light of this, it is not surprising that interventions designed to elicit gratitude are at the forefront of positive psychological intervention research. Although there is growing interest in the applications of gratitude interventions, much investigation and theorizing remains to be done in uncovering how gratitude can be optimally harnessed to impact how people perceive their social relationships and consequently improve wellbeing. Given the scarcity of effective interventions to improve social relationships there is now a critical need for the examination and validation of theoretically-guided interventions. The current study therefore, sought to begin to address these caveats.

\subsection{Gratitude Journals}

Gratitude intervention studies have employed grateful contemplation, behavioural displays of gratitude, and gratitude journals to elicit experiences of gratitude. The most prevalent of these techniques has been gratitude journals where participants are instructed to make written lists of things for which they are grateful, on regular occasions. A comprehensive qualitative review (Wood et al. 2010) and more recently meta-analytical work (Davis et al. 2016) has examined the efficacy of gratitude interventions. Despite some promising findings, these reviews highlight that caution is warranted in the interpretation and generalisation of outcomes due to design limitations, particularly related to the quality of comparison groups (Davis et al. 2016; Wood et al. 2010) which may inflate estimates. Although the most conclusive evidence in support of gratitude interventions has been found when they have been experimentally compared to a daily hassles control group (see Wood et al. 2010 for discussion), their endorsement as effective techniques for improving life satisfaction is widespread (Duckworth et al. 2005; Seligman et al. 2006).

In addition to this, the mechanism(s) through which gratitude interventions operate is relatively unknown, and there is insufficient evidence to verify that gratitude-based interventions in fact operate through the process of increasing gratitude (Davis et al. 2016). Although there have been recent calls in the literature to investigate the mechanisms of psychological intervention effectiveness (Michel et al. 2015; O'Shea et al. 2015), studies attending to explanatory processes between gratitude interventions and favourable outcomes have been limited by cross-sectional designs and the exclusion of gratitude measures and theorized proximal and mediational mechanisms. Identifying plausible 
explanations for how any intervention works is essential in the implementation of that intervention into clinical practice and is particularly needed in the advancement of gratitude intervention research (Emmons and Mishra 2011). Further, although the potential for gratitude to enhance interpersonal relationships, and the importance of interpersonal relationships for individual happiness is evident, limited gratitude intervention studies have explicitly targeted or measured relational variables. Therefore, the current study sought to address these limitations.

\subsection{Gratitude Journals and Life Satisfaction: Potential Mechanisms}

Experts have described gratitude as a social emotion (Emmons and Mishra 2011) robustly related to, and foundational in maintaining high quality interpersonal relationships (Emmons and McCullough 2003; Wood et al. 2008). Gratitude fortifies existing relationships by fostering social bonds and socially inclusive behaviours (Bartlett et al. 2012), and encourages relationship formation (Algoe and Stanton 2012; Waugh and Fredrickson 2006) and relationship satisfaction and connectedness (Algoe et al. 2010). Research shows that feeling grateful impels individuals to reciprocate and this assists in developing enduring supportive relationships (Jenkins and Oatley 1996). Algoe and Haidt (2009) found that an experimental manipulation which asked participants to recall grateful experiences improved participants' perceptions of the person they felt thankful towards. Recent evidence drawing on premises from the find-remind-and-bind theory of gratitude (Algoe et al. 2008; Algoe 2012) emphasises the importance of gratitude in daily social interactions and in strengthening interpersonal bonds (Algoe et al. 2010). This theory posits that feelings of gratitude towards someone stimulate the discovery of new good qualities in that person, or act as a reminder of the known good in the friend/partner/family member. This consequently strengthens feelings of closeness and connection between both people. Therefore, gratitude serves as a strong impetus for enriched social closeness and desires to maintain relationship satisfaction (Kok et al. 2013; Lambert and Fincham 2011). O'Connell et al. (2016) found that expressing gratitude to members of one's social network, compared to self-focused gratitude and a neutral control, led to improvements in relationship satisfaction. Therefore, gratitude journals that cultivate gratitude for existing relationships, or interpersonal aspects of gratitude, may serve to enhance the quality of these social relationships [See Hypothesis 1 and 3(a)].

Life satisfaction is defined as a person's global perspective of their life satisfaction, (Diener et al. 1985). According to the bottom-up perspective, life satisfaction is a function of the combination of satisfaction with multiple life domains, including work, family, health and leisure (see Erdogan et al. 2012 for a review). From this perspective, life satisfaction results from the satisfaction of needs, including interpersonal need satisfaction (Diener et al. 2002). In line with this, past research has established the importance of healthy friendships for life satisfaction and wellbeing (Demir and Özdemir 2010; Demir and Weitekamp 2007; Myers 2000; Reis 2001). Evidence also shows that strong interpersonal relationships and high levels of social support are directly linked to desirable emotional, psychological, academic, and physical health outcomes (Cohen 2004; Cohen et al. 2000; Diener and Chan 2011; Holt-Lunstad et al. 2010; Vandervoort 1999). Therefore, nurturing gratitude in order to produce these social benefits is a promising endeavour.

Finally, gratitude is strongly and consistently related to psychological wellbeing and life satisfaction (Emmons and McCullough 2003, McCullough et al. 2001; Wood et al. 2010), even longitudinally after controlling for the Big Five personality traits (Wood et al. 2008, 2009). Emmons and Mishra (2011) suggest that the social and relational nature of 
gratitude, over other psychologically positive constructs targeted by positive psychological intervention research, may facilitate unique pathways to life satisfaction. Evidence suggests that gratitude contributes to life satisfaction through the building and improving of friendship quality and social connections (Fredrickson 2004a). This potential mechanism can be explained using the broaden-and-build theory of positive emotions (Fredrickson 1998, 2001, 2002, 2004b). Preliminary evidence suggests that gratitude serves to broaden people's thoughts to consider a wide range of prosocial behaviours, which creates the urge to engage in actions that benefit and enhance the wellbeing of others (Emmons and Shelton 2002; Fredrickson 2004b; Tsang 2006). Experiences of gratitude are suggested to foster durable resources whereby people develop new skills for expressing appreciation, kindness, and care to others, which build social bonds over time (Fredrickson 2013; Grant and Gino 2010). There is mounting evidence that experiencing positive emotions and other positive states create lasting improvements in interpersonal and personal domains (for review see Garland et al. 2010).

In light of this evidence, the broaden-and-build theory may account for the relationship between gratitude and life satisfaction, whereby gratitude, through instigating appreciation for others, may facilitate improvement in interpersonal relationships and life satisfaction (Fredrickson 2004a; Wood et al. 2010). This potential pathway has not been directly tested using traditional gratitude journals and interpersonally-orientated gratitude journals, so it is unclear whether these mechanisms are at play when journal instructions encourage experiences of gratitude in an unmodified and unrestrictive manner, or specifically when the focus of the gratitude is specified and directed at interpersonal experiences and other people. In light of this, the present study sought to determine whether there are advantages in wording gratitude journal instructions to deliberately and explicitly focus the user's attention on the people in their life, compared with a more general gratitude instruction. Given that key situational appraisals that give rise to gratitude are relational in nature (Algoe 2012) and gratitude is inherently social and often experienced when one person has done something kind for another (Algoe et al. 2013), it is likely that both a traditional gratitude intervention and an interpersonally-orientated gratitude intervention specifically, may benefit life satisfaction via improving gratitude and social relationships [see Hypothesis 2 and 3(b)]. Indeed, content analysis of gratitude journals has shown that participants who completed a traditional gratitude journal described significantly more people-related experiences compared to a memorable events condition, which also emerged as a significant theme of the journal contents (Rash et al. 2011). Thus a traditional gratitude journal may be as effective in improving relationship outcomes as an interpersonal gratitude journal (see Hypothesis 4).

\subsection{The Present Study}

This randomised controlled trial (RCT) examined the effectiveness of a 2 week (a) a traditional gratitude journal designed to foster gratitude for daily life and (b) an interpersonal gratitude journal designed to foster interpersonal gratitude specifically, relative to a neutral control journal. This trial examined if these interventions led to improvements in life satisfaction, and if so, how, through exploring proposed psychosocial pathways. This was achieved using sequential mediational analysis and through employment of a longitudinal design to ascertain causality. Drawing on the theoretical evidence reviewed, the following hypotheses were generated: 
1. (a) The traditional gratitude intervention (vs. control) is predicted to improve perceived friendship quality at immediate post-test and 1-month follow-up.

(b) These relationships will be mediated by 2 -week and 6-week changes (i.e., baseline to 1-month follow-up) in gratitude, respectively.

2. (a) The traditional gratitude intervention (vs. control) is predicted to improve life satisfaction at immediate post-test, with stronger effects at 1-month follow-up.

Previous studies have shown intervention impacts on wellbeing are distal in nature, and thus may be more pronounced at longer follow-ups (Seligman et al. 2005). Furthermore, evidence suggests that changes in overall wellbeing produced by positive emotions are more likely to occur over time (Fredrickson et al. 2008) and the strongest effects of gratitude interventions are seen after the treatment phase (Watkins et al. 2015). Thus, we hypothesise:

(b) This relationship will be serially mediated by 6-week changes (i.e., baseline to 1-month follow-up) in gratitude and perceived friendship quality.

3. (a) The interpersonal gratitude intervention (vs. control) is predicted to improve perceived friendship quality at immediate post-test and 1-month follow-up. These relationships will be mediated by 2 -week and 6-week changes in gratitude, respectively.

(b) The interpersonal gratitude intervention (vs. control) is predicted to improve life satisfaction at immediate post-test, with stronger effects at 1-month follow-up. This relationship will be serially mediated by 6 -week changes in gratitude and perceived friendship quality.

4. There will be no differences in immediate post-test or 1-month follow-up outcomes between the interpersonal gratitude intervention and the traditional gratitude intervention.

\section{Method}

\subsection{Participants}

A convenience sample of 91 participants, 58.2\% female, was recruited from a university student population in Ireland. The sample were aged between 18 to 57 years $(90 \%$ aged $18-25, M=23.61, S D=7.79)$. As a bootstrapping approach was decided upon a priori, a sample size of 30 per condition were recruited (Hayes 2013), consistent with similar intervention studies (Emmons and McCullough 2003; Sheldon and Lyubomirsky 2006). Inclusion criteria were people over the age of 18 with English language reading and writing proficiency, as all the questionnaires employed were designed for English speakers. In appreciation for participants taking part, they were entered into a draw for $€ 50$. Ethical approval for this study was granted by the host university's Research Ethics Committee. All those recruited provided written informed consent prior to participation.

\subsection{Design}

This was a longitudinal double-blind randomized controlled group study with a relatively equal 1:1:1 allocation ratio, following the Consolidated Standards of Reporting trials (See supplementary material for CONSORT checklist; Schulz et al. 2010). Participants were 
randomized using a random sequence generator and allocation was concealed in sequentially numbered identical opaque envelopes, containing either of the experimental journals or the control journal, shuffled by an independent research assistant. In this way, both participants and the investigators enrolling participants were blind to group allocation (traditional gratitude journal, interpersonal gratitude journal, or control journal) across all assessments. Group allocation was revealed to the principal investigator following the final assessment. Life satisfaction was the primary outcome, and gratitude and perceived friendship quality served as secondary outcomes.

\subsection{Measures}

All information was obtained for the following self-report measures, using a questionnaire pack, administered in a quiet lab. The three time points were: baseline (T1), immediate post-test at 2 weeks (T2), and follow-up at 1 month (T3).

Gratitude was assessed using The Gratitude Questionnaire-Six Item Form (GQ-6; McCullough et al. 2002). This is a self-report scale examining general thankfulness and gratitude, under four facets of grateful tendencies- intensity, density, span, and frequency, and has been employed in previous intervention studies assessing change (e.g., Killen and Macaskill 2015; Krentzman et al. 2015; Pearce et al. 2016; Toepfer et al. 2012). Respondents are asked to indicate how much they agree with six statements, for example 'I have so much in life to be thankful for', two of which are reverse scored, for example, 'When I look at the world, I don't see much to be grateful for'. Respondents provide their answer on a 7-point scale ranging from 'Strongly disagree' $=1$ to 'Strongly agree' $=7$. All items were summed to produce a total gratitude score. The scale was reported to have high internal consistency in McCullough and colleagues (2002) original study (Cronbach's alpha $=0.82$ ). Similar alpha coefficients were found in the current study at baseline, posttest and follow-up, 0.78, 0.75, and 0.77, respectively.

Positive Affect was assessed using the Scale of Positive and Negative Experience (SPANE; Diener et al. 2010) subscale (SPANE-P). The SPANE- P is a six item self-report questionnaire that measures positive affective experiences. Respondents were asked to indicate how much of the time they have experienced a combination of general and specific feelings and emotions (six positive and six negative), for example, 'happy', 'joyful', in the past 2 weeks, on a 5-point frequency scale, ranging from 'Very Rarely or Never' $=1$ to 'Very Often or Always' = 5. An overall score is produced by summing responses on items, which can range from 6 to 30, with higher scores indicating higher frequency of experiencing positive affect over a 2 week period. Diener and colleagues (2010) reported high internal reliability (Cronbach's alpha $=0.87$ ) and the current study observed similar levels at baseline, post-test, and follow-up, 0.87, 0.88, and 0.86, respectively. Positive affect was used in comparative analyses, to ascertain whether the gratitude journals exerted effects on life satisfaction, through changes in gratitude specifically, rather than general positive affective valance. ${ }^{1}$

Perceived Friendship Quality was measured using the National Institute of Health (NIH) Toolbox Adult Social Relationship Friendship Scales. This 8-item assessment tool

\footnotetext{
${ }^{1}$ As positive affect has been used as an outcome of happiness/subjective wellbeing in past studies, changes were examined over time. This revealed a significant effect of time, $F(1,166)=5.48, p=0.006$. Post-hoc analysis revealed statistically significant differences between the mean scores at baseline and immediate post-test (mean difference $=-1.15, p<0.001$ ) and baseline and one-month follow-up only (mean difference $=-0.899, p=0.003$ ), indicating a steady increase in positive affect across time. There was no evidence of a Condition $\times$ Time interaction, $F(4,166)=0.659, p=0.621$.
} 
measures the perceived availability of companions to interact or associate with, and people one feels emotionally close or connected to (Cyranowski et al. 2013). This was created specifically for assessing aspects of social relationships that may change over time or in response to clinical intervention. Participants were instructed to read eight statements and rate the extent each applied to them in the past 2 weeks for example, 'I feel close to my friends' on a 5-point frequency scale, ranging from 'Never' $=1$ to 'Always' $=5$. An overall score is computed by summing the responses to each statement, where higher scores indicate higher perceived quality of friendships. Cyranowski and colleagues (2013) reported high internal reliability (Cronbach's alpha $=0.95$ ) and this was confirmed in the present study with high alpha coefficients at baseline, immediate post-test, and follow-up, $0.84,0.88$, and 0.82 , respectively.

Life Satisfaction was assessed using the Satisfaction with Life Scale (SWLS; Diener et al. 1985). This 5-item instrument measures people's global perspective of their life satisfaction. Participants rated their level of agreement on items; for example, 'In most ways my life is close to my ideal', on a 7-point scale, ranging from 'Strongly disagree' $=1$ to 'Strongly agree' $=7$. An overall score is computed by summing the responses of each item. Scores range from 5 to 35, where increments in scores correspond to increments in satisfaction with life. This scale has a high internal consistency, with alpha coefficients between 0.79 and 0.89 (see review, Pavot and Diener 1993). The current study reflected this, with high alpha coefficients at baseline, immediate post-test, and follow-up, $0.88,0.83$, and 0.82 , respectively.

\subsection{Procedure}

Participants were invited to take part in a study entitled 'Writing and Wellbeing' and given an information sheet outlining the research aims and gave written consent before commencing the study. Prior to this, an independent research assistant randomized questionnaire packs and journals into sealed labelled envelopes, to achieve double-blind design and to conceal allocation sequence from the investigators in advance.

Participants completed the baseline questionnaires and were randomly assigned to either the interpersonal gratitude, traditional gratitude or the control condition. Distinct journals were designed for each condition and distributed with the questionnaire pack at baseline. The traditional gratitude journal wording was taken from previous research and the wording for the interpersonal journal was a further adaptation (Emmons and McCullough 2003; Sheldon and Lyubomirsky 2006). These journals contained intervention guidelines and separate pages for each day participants were required to write. To assess the valence of reported events, at the end of each page participants were asked to rate on a scale of not at all pleasant $=1$ to very pleasant $=5$, how what they wrote about made them feel. The ratings for each day were then averaged to form a mean valence score for each participant.

In the interpersonal gratitude condition, participants were given the following instructions on the first page of their journal-

Writing is a great way to reflect on your daily events. There are many things in our lives, both large and small, which we might be grateful for. For the next two weeks, on just two days of your choice per week (four days in total), write down in the space provided a number of social interactions or friendships/relationships that you were involved in [that day] and are grateful for. 
In the traditional gratitude condition, participants were given identical instructions as the interpersonal gratitude condition, but had no targeted focus on interpersonally orientated gratitude and were instead asked to write about things they were grateful for that day-

Writing is a great way to reflect on your daily events. There are many things in our lives, both large and small, which we might be grateful for. For the next two weeks, on just two days of your choice per week (four days in total), write down in the space provided a number of things that you are grateful for that day.

In the control condition, participants were given the following instructions on the first page of their journal-

Writing is a great way to reflect on your daily events. For the next two weeks, on just two days of your choice per week (four days in total), write down in the space provided a number of experiences/interactions that occurred that day.

After completing baseline questionnaires, participants were instructed to read their journal instructions carefully and informed of the necessity to strictly adhere to these guidelines to ensure the integrity of the findings, and reminded that they would receive text messages on three occasions prompting them to complete their journal entries. Participants were given the option of returning their journal to the experimenter after the 2-week period or keeping it for privacy reasons and given a choice in what days of the week they wanted to complete their journal, in order to foster an autonomy- supportive environment (Della Porta et al. 2012 as cited in Lyubomirsky and Layous 2013; Kaczmarek et al. 2014; Nelson et al. 2015).

After the 2-week journal entry stage, participants returned for the immediate post-test assessment, and again 1 month later for final follow-up, where they completed the questionnaire pack as previously administered at baseline. Upon completion, participants were thanked and debriefed.

\subsection{Statistical Analysis}

IBM SPSS Statistics 21 was utilized to conduct all statistical analysis, with alpha set at 0.05 as the criterion for significance. Three mediation models (Preacher and Hayes 2008) guided the analytical procedure for the proposed theoretical models. The first simple mediation model was concerned with the gratitude (traditional and interpersonal independently) intervention-related effects on perceived friendship quality at immediate posttest compared to the control. It tested the hypotheses that that gratitude changes from T1T2 acted as a mediator of the intervention effects on perceived friendship quality at immediate post-test. The second simple mediation model was concerned with the gratitude (traditional and interpersonal independently) intervention-related effects on perceived friendship quality at 1-month follow-up, compared to the control. It tested the hypotheses that gratitude changes from T1-T3 acted as a mediator of the intervention effects on perceived friendship quality at 1-month follow-up. The third serial mediation model predicted that the gratitude (traditional and interpersonal independently) intervention-related effects on life satisfaction at 1-month follow-up. It tested the hypotheses that changes in gratitude and perceived friendship quality from baseline to 1-month follow-up acted as serial mediators of the intervention effects on life satisfaction at 1-month follow-up. For all mediational analyses, baseline scores on the outcome variable were entered as a covariate in each model. Psychosocial mediator variables were expressed as standardized residualized change scores, which are employed as a standard statistical technique of quantifying 
change (e.g., Teixeira et al. 2010), and are a more reliable and superior method of evaluating change over time than difference scores (Cohen et al. 2003). Changes from baseline to immediate post-test (T1-T2) were computed as residuals of the 2-week score regressed on the corresponding baseline score, and changes from baseline to follow-up (T1-T3) were computed as residuals of the 1-month follow-up score regressed on the corresponding baseline score; these standardized residuals were then saved as an evaluation of change over time associated with each mediator.

In order to test these models formal significance testing of all indirect effects was conducted using the custom dialogue PROCESS for SPSS (Hayes 2013). ${ }^{2}$ Results are reported for bootstrap significance tests using a bias-corrected and accelerated (BCa) $95 \%$ confidence interval (CI) with a resample procedure of 5000 bootstrap samples; whereby an estimate is statistically significant at $p<0.05$, or if the $95 \%$ CI does not contain zero. This method is preferred over others, for example Normal Theory (Sobel's test) which is based on the assumption that the sampling distribution of $a b$ is symmetrical when in fact such product terms tend to be skewed. The current method overcomes this limitation, as it does not necessitate the sample distribution to be normal. Also, research suggests that for small samples sizes it is more robust against Type 1 and Type 2 error, less biased, and more powerful than other procedures (Hayes 2009, 2013; Preacher and Hayes 2004, 2008; Preacher et al. 2007). In order to best answer the research questions, and as the PROCESS macro is not suited to multicategorical independent variables, all conditions are compared to each of the other independently for all analyses. As each of the models' independent variables are dichotomous, all estimates of effects are reported using unstandardized regression coefficients (B), as recommended by Hayes (2013). General Linear Model (GLM repeated measures) was used for within- and between-group changes, with partial eta squared $\left(\eta^{2} p\right)$ as a measure of effect size. These were conducted prior to mediation analyses, in keeping with traditional approaches. Although there is increasing agreement amongst scholars that the presence of a significant total effect should not be a precondition to searching for evidence of indirect effects (Hayes 2009, 2013; Rucker et al. 2011), given the primary aim of assessing if this interpersonal gratitude journal intervention caused changes in life satisfaction and perceived friendship quality and given the clinical and applied focus of these interventions, the authors sought to err on the side of caution in their analyses. As such, mediation was not explored in the absence of significant GLM repeated measures findings. However, if there were significant GLM repeated measures findings, but no evidence of a significant total effect using path analysis, mediation was explored with caution in case some potentially important mechanisms were missed (Hayes 2009; Loeys et al. 2015). Post-hoc analyses were conducted using Bonferroni pairwise comparisons, executed using the syntax features of SPSS and simple contrasts for analysis of significant main effects.

\footnotetext{
2 The PROCESS macro employs list-wise deletion based on each variable in the model. Although in many cases this is not optimal, for the present study it was acceptable as it led to the exclusion of $<5 \%$ of cases, therefore the presented data were derived from the complete cases only.
} 


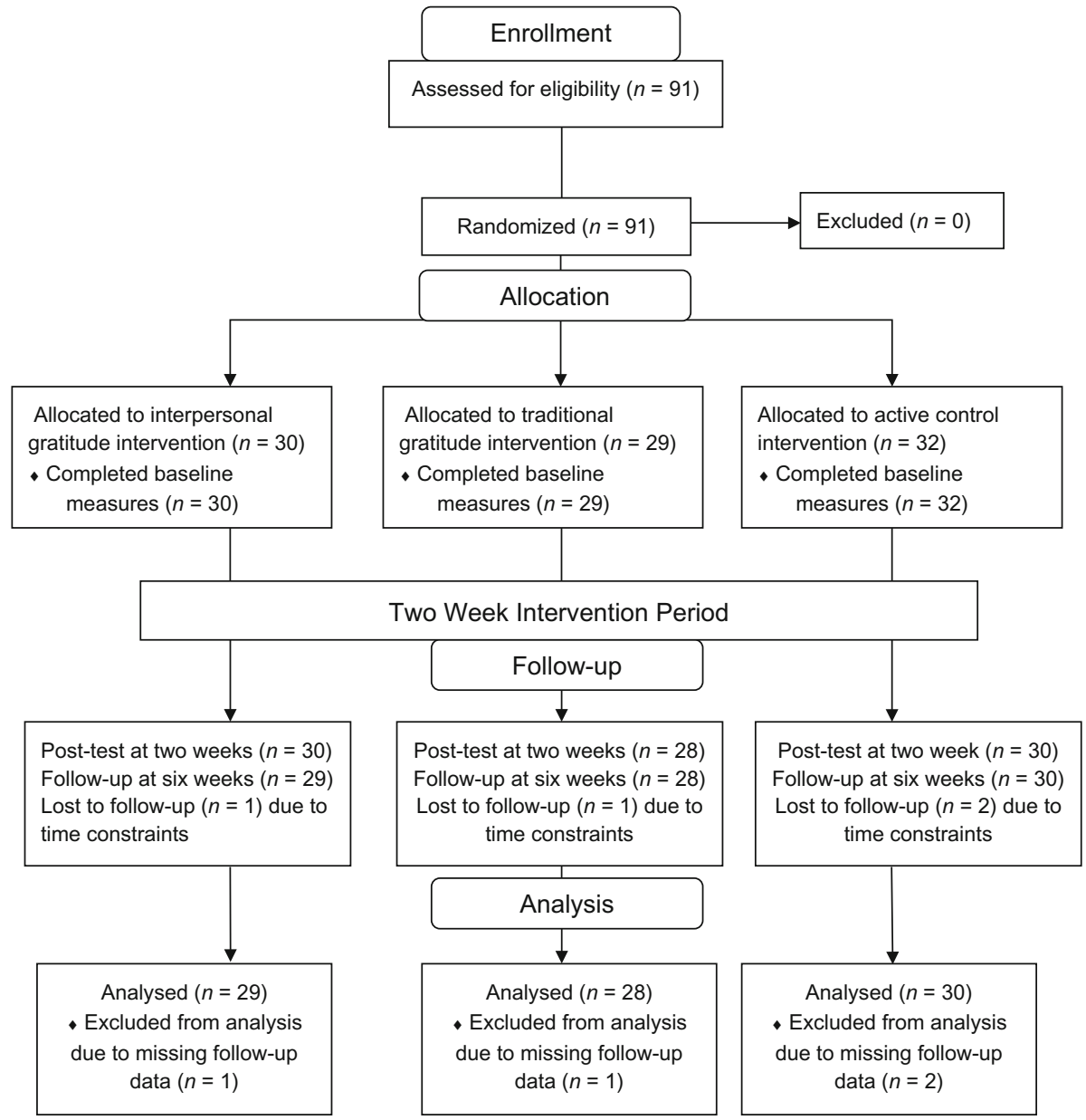

Fig. 1 Flow of participants through trial stages adapted from CONSORT flow diagram. Schulz et al. (2010)

\section{Results}

\subsection{Preliminary Descriptive Analyses}

Figure 1 presents the CONSORT diagram for the trial stages (Schulz et al. 2010). Of the 91 participants who completed baseline questionnaires, 86 (94.5\%) completed the immediate post-test and follow-up assessment. Study dropout was very low $(n=4$ or $4.4 \%)$ with no differential dropout between the control $(n=2)$, interpersonal gratitude $(n=1)$ and traditional gratitude $(n=1)$ conditions.

Manipulation Checks Of the 91 participants, 39.6\% $(n=36)$ returned their diaries with all four entries completed, while the remainder told the experimenters they did not want the contents to be seen. Whether journals were returned or not was independent of treatment assignment to the traditional gratitude journal (15 returned), interpersonal gratitude journal (9 returned) or control journal (12 returned): $\chi 2(2)=3.0, p=0.221$. There were also no differences in levels of gratitude $(p=0.38)$, positive affect $(p=0.46)$, perceived 
friendship quality $(p=0.27)$ or life satisfaction $(p=0.63)$ between participants who returned their diary and participants who did not. Events reported in the control journal were neutrally valenced on average $(M=3.65, S D=0.47)$, while the traditional journal $(M=4.65, S D=0.32)$ and interpersonal journal $(M=4.44, S D=0.50)$, were more positively valenced on average, $F(2,33)=19.96, p<0.001$. Pairwise comparisons indicated that as expected, there was a significant difference in valence between the control and gratitude interventions (all $p s<0.05$ ) but no differences in valence between the two gratitude conditions $(p=0.26)$.

Tests of baseline homogeneity were conducted and no significant differences between treatment groups were found in sex; $\chi^{2}(2)=0.98, p=0.612$, age; $F(2,87)=0.48$, $p=0.62$, life satisfaction; $F(2,88)=0.22, p=0.80$, perceived friendship quality; $F(2$, $88)=0.28, p=0.76$, gratitude; $F(2,87)=0.55, p=0.58$, or positive affect; $F(2$, $88)=0.04, p=0.96$, confirming successful randomization. Outcome descriptive characteristics across time and treatment groups are presented in Table 1.

\subsection{Bivariate and Partial Associations}

Pearson product-moment correlations for baseline, immediate post-test and follow-up scores on each of the psychosocial measures and changes across time are displayed in Table 2. Spearman's rho correlation coefficients are reported for all correlations involving gratitude change as the assumption of normality was violated (Shapiro-Wilk's, $p<0.05$ ). None of the primary variables for each independent model tested exceeded the recommended intercorrelation value of $>0.80$, signifying a low risk of multicollinearity in the data (Katz 2011). After adjusting for intervention condition using partial correlations, none of the above correlations coefficients (and $p$ values) changed substantially.

\subsection{Hypothesis Testing}

Hypothesis 1(a) The traditional gratitude intervention (vs. control) is predicted to improve perceived friendship quality at immediate post-test and 1-month follow-up.

GLM repeated measures revealed a significant main effect for time, $F(2,110)=5.595$, $p=0.01$, and a statistically significant Condition $\times$ Time interaction, $F(2,110)=4.42$, $p=0.01, \eta^{2} p=0.07$, such that those who completed the traditional gratitude intervention experienced higher perceived friendship quality over time (baseline, immediate post-test, follow-up) than those in the control condition. Post-hoc Bonferroni pairwise comparisons revealed that participants who completed the traditional gratitude intervention had significantly higher levels of perceived friendship quality at the immediate post-test, $p<0.001$, and 1-month follow-up, $p=0.01$, compared to baseline, with no such differences between immediate post-test and 1-month follow-up $(p=1.00)$. In contrast, there was no significant difference in scores on friendship quality from baseline to immediate post-test, $p=1.00$, or follow-up, $p=1.00$, or from immediate post-test to follow-up, $p=1.00$, in the control condition.

Hypothesis 1(b) These relationships will be mediated by 2-week and 6-week changes in gratitude.

A simple mediation analysis confirmed that there was a significant total effect of the traditional gratitude intervention on perceived friendship at immediate post-test, controlling for baseline perceived friendship quality scores $(c)$, and this relationship became 


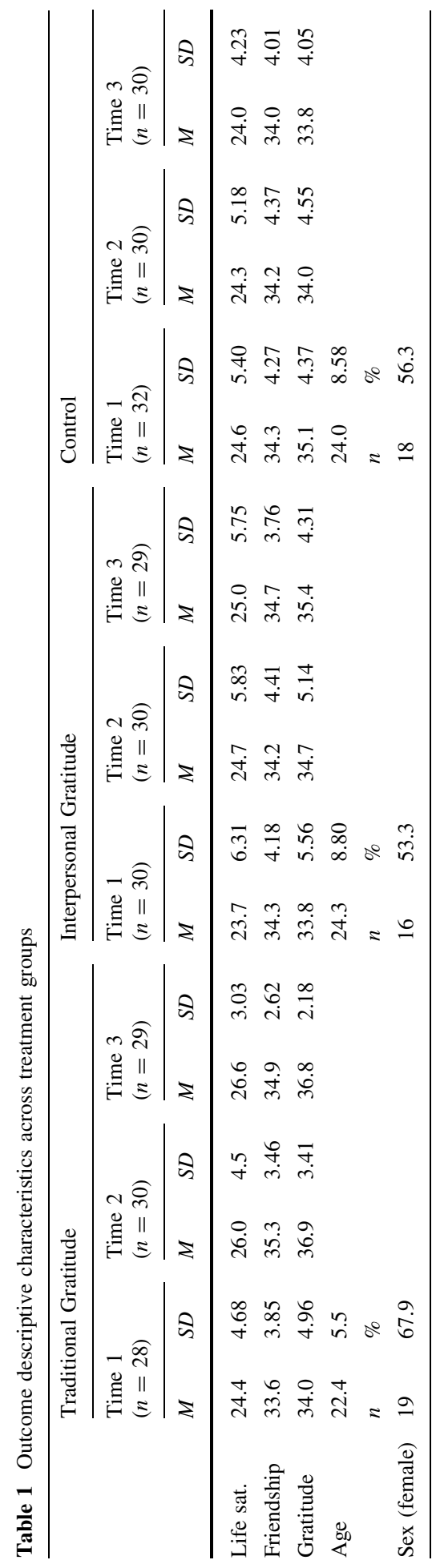




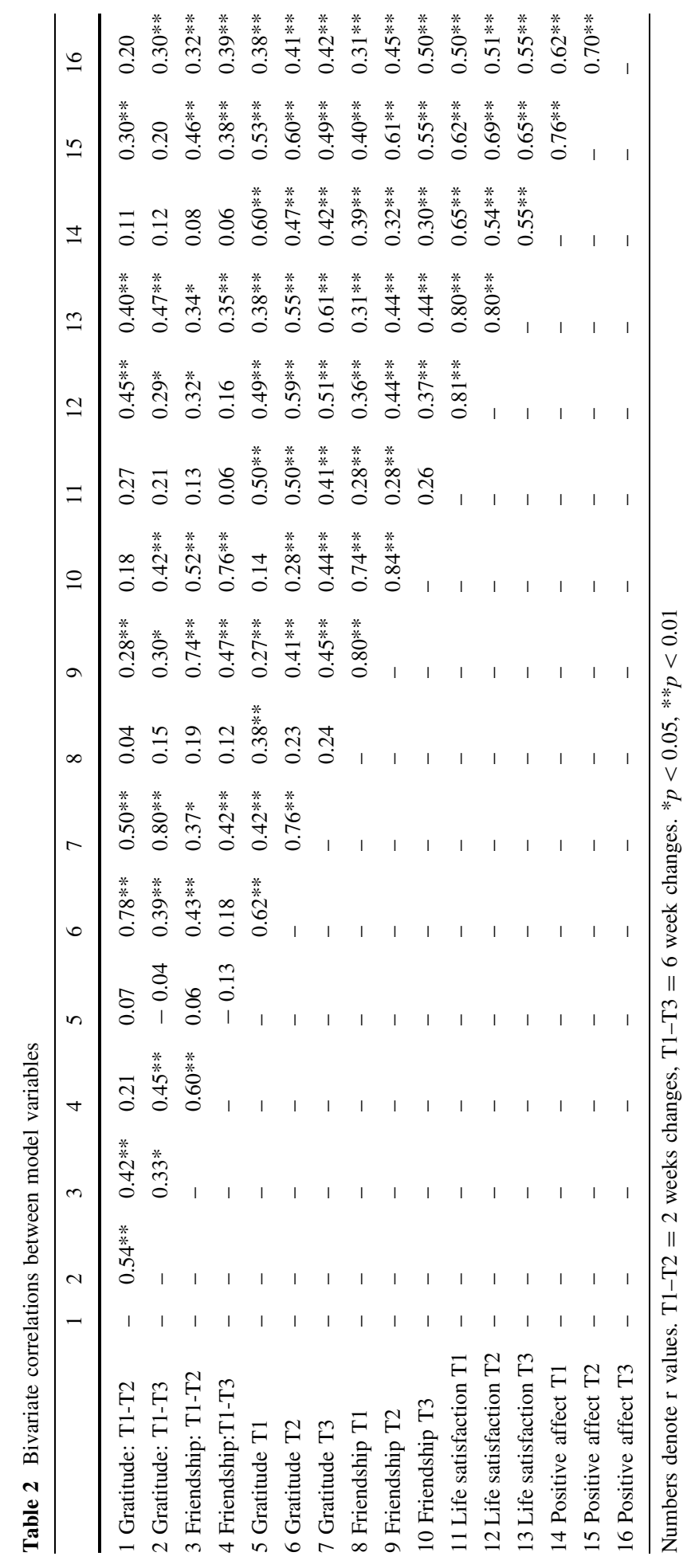


nonsignificant when the effect of gratitude change (T1-T2) was also taken into account $\left(c^{\prime}\right)$. As hypothesised, gratitude change (T1-T2) mediated the effect of the traditional gratitude intervention on perceived friendship quality, as indicated by a significant indirect effect $(a b)$ such that those who completed the traditional gratitude intervention had higher levels of change in gratitude, which, in turn, positively impacted on perceived friendship quality after the 2 week intervention period. Overall, this model significantly accounted for $73.8 \%$ of the variance in perceived friendship quality at immediate post-test, $F(3$, $53)=49.81, p<0.0001$. See Table 3 for all parameter estimates.

Table 3 Simple mediation models

\begin{tabular}{|c|c|c|c|c|}
\hline Model & Estimate & $S E$ & $p$ & $\mathrm{BCa} 95 \% \mathrm{CI}$ (lower) $\mathrm{BCa} 95 \% \mathrm{CI}$ (upper) \\
\hline
\end{tabular}

Effect of condition on T2 friendship as mediated by gratitude change (T1-T2)

Model without mediator

$\begin{array}{lllllr}\text { Intercept } & 6.488 & 2.609 & 0.016 & 1.258 & 11.718 \\ \text { Intervention } \rightarrow \mathrm{F}(\mathrm{T} 2)(\mathrm{c}) & 1.614 & 0.605 & 0.010 & 0.402 & 2.826 \\ \mathrm{R}^{2}(\mathrm{y}, \mathrm{x}) & 0.688 & & & & \\ \text { Model with mediator } & & & & & \\ \text { Intercept } & 7.575 & 2.436 & 0.003 & 2.690 & \\ \text { Model 1: G(T1-T2) as outcome } & & & & & 1.466 \\ \text { Intervention } \rightarrow \mathrm{G}(\mathrm{T} 1-\mathrm{T} 2)(\mathrm{a}) & 1.043 & 0.21 & <0.0001 & 0.619 & 1.871 \\ \text { Model 2: } \mathrm{F}(\mathrm{T} 2) \text { as outcome } & & & & & 1.766 \\ \mathrm{G}(\mathrm{T} 1-\mathrm{T} 2) \rightarrow \mathrm{F}(\mathrm{T} 2)(\mathrm{b}) & 1.149 & 0.360 & 0.002 & 0.427 & 2.360 \\ \text { Intervention } \rightarrow \mathrm{F}(\mathrm{T} 2)\left(\mathrm{c}{ }^{\prime}\right) & 0.416 & 0.673 & 0.539 & -0.934 & \\ \text { Indirect effect }(\mathrm{ab}) & 1.198 & 0.499 & - & 0.352 & \\ \mathrm{R}^{2}(\mathrm{~m}, \mathrm{x}) & 0.311 & - & <0.0001 & & \\ \mathrm{R}^{2}(\mathrm{y}, \mathrm{m}, \mathrm{x}) & 0.738 & - & <0.0001 & & \end{array}$

Effect of condition on T3 friendship as mediated by gratitude change (T1-T3)

Model without mediator

$\begin{array}{lrlllr}\text { Intercept } & 12.073 & 2.580 & <0.0001 & 6.901 & 17.244 \\ \text { Intervention } \rightarrow \mathrm{F}(\mathrm{T} 3)(\mathrm{c}) & 1.352 & 0.60 & 0.028 & 0.150 & 2.554 \\ & 0.586 & & & & \\ \mathrm{R}^{2}(\mathrm{y}, \mathrm{x}) & & & & & 18.674 \\ \text { Model with mediator } & 13.950 & 2.355 & <0.0001 & 9.226 & \\ \text { Intercept } & & & & & 1.566 \\ \text { Model 1: G(T1-T3) as outcome } & & & & \\ \text { Intervention } \rightarrow \mathrm{G}(\mathrm{T} 1-\mathrm{T} 3)(\mathrm{a}) & 1.121 & 0.222 & <0.0001 & 0.675 & 1.915 \\ \text { Model 2: PH as outcome } & & & & & 1.247 \\ \mathrm{G}(\mathrm{T} 1-\mathrm{T} 3) \rightarrow \mathrm{F}(\mathrm{T} 3)(\mathrm{b}) & 1.257 & 0.328 & <0.001 & 0.599 & 2.339 \\ \left.\text { Intervention } \rightarrow \mathrm{F}(\mathrm{T} 3)(\mathrm{c})^{\prime}\right) & -0.056 & 0.650 & 0.931 & -1.359 & \\ \text { Indirect effect (ab) } & 1.408 & 0.431 & - & 0.658 & \\ \mathrm{R}^{2}(\mathrm{~m}, \mathrm{x}) & 0.323 & - & <0.0001 & & \\ \mathrm{R}^{2}(\mathrm{y}, \mathrm{m}, \mathrm{x}) & 0.676 & - & <0.0001 & & \end{array}$

BCa 95\% CI bias-corrected and accelerated 95\% confidence interval with a resample procedure of 5000 bootstrap samples. $F(T 2)$ friendship at post-test, $F(T 3)$ friendship at follow-up, $G(T 1-T 2)$ gratitude change from baseline to post-test, $G(T 1-T 3)$ gratitude change from baseline to follow-up 
In order to rule out an alternative model in which the effect of the traditional gratitude intervention (vs. control) on perceived friendship quality at immediate post-test, was mediated by changes in positive affect from baseline to immediate post-test (T1-T2), rather than gratitude exclusively, a parallel mediation was conducted in which change in positive affect (T1-T2) and gratitude (T1-T2) were specified as mediators simultaneously. This analysis conducted a concurrent test for each mechanism while accounting for the shared association between them (Hayes 2013). Results did not support this alternative explanation, as gratitude (T1-T2) remained a significant mediator while controlling for positive affect $(\mathrm{T} 1-\mathrm{T} 2)$ in the model $(\mathrm{B}=0.81, \mathrm{SE}=0.45,95 \%$ BCa CI $0.02,1.79)$. Further, the specific indirect effect of the intervention on perceived friendship quality at immediate post-test, through positive affect (T1-T2), while controlling for gratitude (T1$\mathrm{T} 2$ ) in the model, was not statistically significant $(\mathrm{B}=0.36, \mathrm{SE}=0.27,95 \% \mathrm{BCa} \mathrm{CI}$ $-0.08,1.0)$.

We also examined 6-week changes in gratitude as a mediator in this analysis. A simple mediation analysis confirmed that there was a significant total effect of the traditional gratitude intervention on perceived friendship quality at final follow-up, controlling for baseline perceived friendship quality scores quality $(c)$, and this relationship became nonsignificant when the effect of gratitude change (T1-T3) was also taken into account $\left(c^{\prime}\right)$. As predicted, gratitude change (T1-T3) mediated the effect of the traditional gratitude intervention on perceived friendship quality at follow-up, as indicated by a significant indirect effect $(a b)$, such that those who completed the traditional gratitude intervention had higher levels of change in gratitude, which, in turn, positively impacted on perceived friendship quality at final 1-month follow-up. Overall, this model significantly accounted for $67.6 \%$ of the variance in perceived friendship quality at follow-up, $F(3,53)=36.80$, $p<0.0001$. See Table 3 for all parameter estimates.

In order to rule out an alternative model in which the effect of the traditional gratitude intervention (vs. control) on perceived friendship quality at 1-month follow-up, was mediated by changes in positive affect from baseline to 1-month follow-up (T1-T3), rather than gratitude exclusively, a parallel mediation was conducted in which change in positive affect (T1-T3) and gratitude (T1-T3) were specified as mediators simultaneously. Results did not support this alternative explanation, as gratitude (T1-T3) remained a significant mediator while controlling for positive affect (T1-T3) in the model $(\mathrm{B}=1.27$, $\mathrm{SE}=0.41$, $95 \%$ BCa CI $-0.57,2.22$ ). Further, the specific indirect effect of the intervention on perceived friendship quality, through positive affect (T1-T3), while controlling for gratitude (T1-T3) in the model, was not statistically significant $(\mathrm{B}=0.16, \mathrm{SE}=0.19,95 \%$ BCa CI $-0.19,0.58)$.

Hypothesis 2(a) The traditional gratitude intervention (vs. control) is predicted to improve life satisfaction at immediate post-test, with stronger effects at 1-month follow-up.

GLM repeated measures revealed that there was no significant main effect for time $F(2$, $110)=2.75, p=0.07$. There was evidence of a statistically significant Condition $\times$ Time interaction, $F(2,110)=5.19, p=0.01, \eta^{2} \mathrm{p}=0.09$, such that those who completed the traditional gratitude intervention experienced higher life satisfaction over time (baseline, immediate post-test, follow-up) than those in the control condition. Post-hoc Bonferroni pairwise comparisons revealed that participants who completed the traditional gratitude intervention had significantly higher levels of life satisfaction at the immediate post-test, $p=0.045$, and 1-month follow-up, $p<0.001$, compared to baseline, with no such differences between immediate post-test and 1-month follow-up $(p=0.89)$. In contrast, there was no significant difference in scores on life satisfaction from baseline to immediate post- 
test, $p=1.00$, or follow-up, $p=1.00$, or from immediate post-test to follow-up, $p=1.00$, in the control condition.

Hypothesis 2(b) This relationship will be serially mediated by 6-week changes in gratitude and perceived friendship quality.

We first investigated 2 week changes in gratitude as a mediator. Using ordinary least square path analysis, there was a distinct trend towards a significant effect of the traditional gratitude intervention (vs. control) on life satisfaction at immediate post-test, while controlling for baseline life satisfaction, $B=1.38, t=1.85, p=0.07$, 95\% BCa CI -0.12 , 2.88. Also, the traditional gratitude intervention did not have an indirect effect on life satisfaction, through gratitude change (T1-T2), as indicated by a nonsignificant indirect effect, $\mathrm{B}=0.93, \mathrm{SE}=0.58,95 \% \mathrm{BCa} \mathrm{CI}-0.18,2.09$.

Secondly, we investigated 6 week changes in gratitude as a mediator. A serial multiple mediation analysis was conducted using ordinary least square path analysis to examine whether the effect of the traditional gratitude intervention (vs. control) on life satisfaction at final follow-up was mediated by 6 -week changes in gratitude and perceived friendship quality (see Fig. 2). As can be seen in Table 4, there was a significant total effect of the traditional gratitude intervention on life satisfaction at final follow-up, controlling for baseline life satisfaction scores $(c)$. This effect was sequentially mediated by changes in gratitude (T1-T3) and changes in perceived friendship quality (T1-T3), as evidenced by a significant sequentially mediated indirect effect $\left(a_{1} d_{21} b_{2}\right)$. Therefore, as predicted, those who completed the traditional gratitude intervention experienced increased gratitude and perceived friendship quality, which in turn enhanced life satisfaction at final follow-up. After controlling for the mediators, there was evidence of a significant direct effect $\left(c^{\prime}\right)$ of intervention on life satisfaction, suggesting that additional mechanisms may have been at play. Overall, this model significantly accounted for $80.2 \%$ of the variance in life satisfaction, $F(4,54)=52.49, p<0.0001$.

In order to rule out an alternative model with different sequential order, a serial mediation was conducted in which change in perceived friendship quality (T1-T3) was specified as preceding gratitude change (T1-T3) as a sequential mediator. Results did not support this alternative direction of flow, as the indirect effect of the intervention through

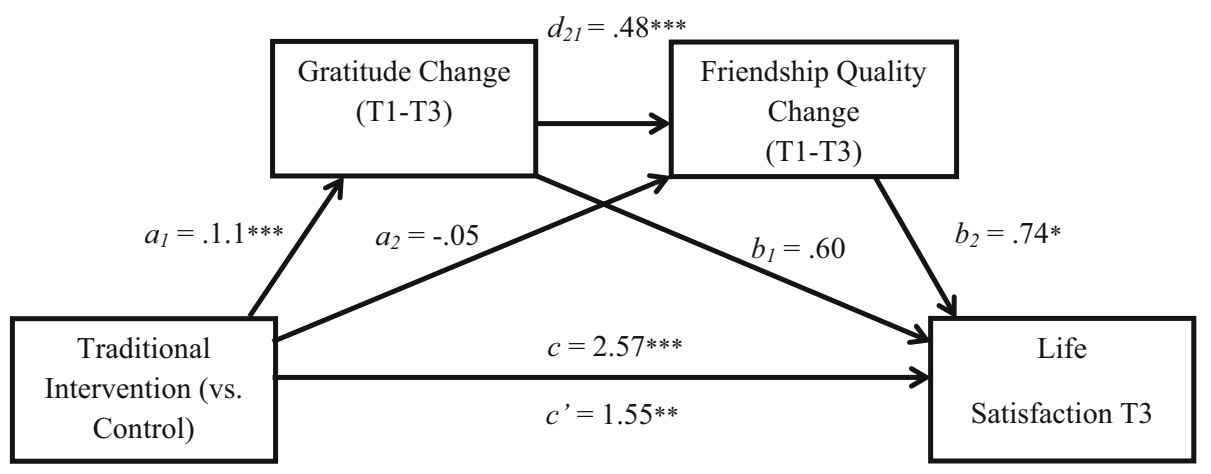

Fig. 2 Serial mediation model showing the effect of the traditional gratitude intervention on life satisfaction through changes in gratitude and friendship quality. T1 = baseline; T3 $=6$ week follow-up. Baseline life satisfaction served as a covariate in the model. Unstandardized coefficients $(B)$ are presented. $* p<0.05$, ** $p<0.01$, *** $p<0.001$ 
Table 4 Serial mediation model: indirect effects between traditional gratitude intervention (vs. control) and life satisfaction at follow-up

\begin{tabular}{lllll}
\hline Model Estimate $S E$ & $p$ & $\begin{array}{l}\text { BCa 95\% CI } \\
\text { (lower) }\end{array}$ & $\begin{array}{l}\text { BCa 95\% CI } \\
\text { (upper) }\end{array}$ \\
\hline
\end{tabular}

Effect of condition on T3 friendship as mediated by gratitude (T1-T3) and Friendship (T1-T3)

Model without mediators

\begin{tabular}{|c|c|c|c|c|c|}
\hline Intercept & 8.372 & 1.4222 & $<0.0001$ & 5.520 & 11.223 \\
\hline Intervention $\rightarrow \mathrm{LS}(\mathrm{T} 3)(\mathrm{c})$ & 2.569 & 0.533 & $<0.0001$ & 1.500 & 3.637 \\
\hline $\mathrm{R}^{2}(\mathrm{y}, \mathrm{x})$ & 0.740 & & & & \\
\hline \multicolumn{6}{|c|}{ Model with mediatorl: $G(T 1-T 3)$} \\
\hline Intercept & -1.065 & 0.593 & 0.078 & -2.254 & 0.124 \\
\hline \multicolumn{6}{|c|}{ Model 1: G(T1-T3) as outcome } \\
\hline $\begin{array}{l}\text { Intervention } \rightarrow \mathrm{G} \text { (T1- } \\
\quad \mathrm{T} 3)\left(\mathrm{a}_{1}\right)\end{array}$ & 1.098 & 0.222 & $<0.0001$ & 0.653 & 1.544 \\
\hline
\end{tabular}

Model with both mediators

Model 2: F(T1-T3) as outcome

\begin{tabular}{|c|c|c|c|c|c|}
\hline $\mathrm{G}(\mathrm{T} 1-\mathrm{T} 3) \rightarrow \mathrm{F}(\mathrm{T} 1-\mathrm{T} 3)\left(\mathrm{d}_{21}\right)$ & 0.479 & 0.122 & 0.0003 & 0.234 & 0.725 \\
\hline $\begin{array}{l}\text { Intervention } \rightarrow \mathrm{F}(\mathrm{T} 1- \\
\quad \mathrm{T} 3)\left(\mathrm{a}_{2}\right)\end{array}$ & -0.045 & 0.241 & 0.853 & -0.528 & 0.438 \\
\hline \multicolumn{6}{|l|}{ Model 3: LS(T3) as outcome } \\
\hline $\mathrm{G}(\mathrm{T} 1-\mathrm{T} 3) \rightarrow \mathrm{LS}(\mathrm{T} 3)\left(\mathrm{b}_{1}\right)$ & 0.691 & 0.330 & 0.075 & -0.062 & 1.264 \\
\hline $\mathrm{F}(\mathrm{T} 1-\mathrm{T} 3) \rightarrow \mathrm{LS}(\mathrm{T} 3)\left(\mathrm{b}_{2}\right)$ & 0.743 & 0.327 & 0.027 & 0.087 & 1.398 \\
\hline Intervention $\rightarrow$ LS(T3) (c') & 1.551 & 0.573 & 0.009 & 0.402 & 2.700 \\
\hline $\mathrm{R}^{2}(\mathrm{x}, \mathrm{m} 1, \mathrm{~m} 2, \mathrm{y})$ & 0.802 & - & $<0.0001$ & & \\
\hline \multicolumn{6}{|l|}{ Indirect effects } \\
\hline$a b$ & 1.017 & 0.504 & - & 0.048 & 2.051 \\
\hline$a_{1} b_{1}$ & 0.660 & 0.522 & - & -0.282 & 1.772 \\
\hline$a_{1} d_{21} b_{2}$ & 0.391 & 0.227 & - & 0.005 & 0.934 \\
\hline$a_{2} b_{2}$ & -0.033 & 0.203 & - & -0.489 & 0.370 \\
\hline
\end{tabular}

$L S(T 3)$ life satisfaction at follow-up, $G(T 1-T 3)$ gratitude change from baseline to follow-up, $F(T 1-T 3)$ friendship quality change from baseline to follow-up, $a b$ total indirect effect, $a_{1} b_{1}$ specific indirect effect through gratitude, $a_{1} d_{21} b_{2}$ specific indirect effect through gratitude and friendship quality in serial, $a_{2} b_{2}$ specific indirect effect through friendship quality, BCa 95\% CI bias-corrected and accelerated $95 \%$ confidence interval with a resample procedure of 5000 bootstrap samples

perceived friendship quality and subsequently gratitude was not statistically significant $(B=0.136, \mathrm{SE}=0.154,95 \% \mathrm{BCa} C \mathrm{I}-0.03,0.66)$.

Hypothesis 3(a) The interpersonal gratitude intervention (vs. control) is predicted to improve perceived friendship quality at immediate post-test and 1-month follow-up. These relationships will be mediated by 2 -week and 6-week changes in gratitude, respectively.

Hypothesis 3 (b) The interpersonal gratitude intervention (vs. control) is predicted to improve life satisfaction at immediate post-test, with stronger effects at 1-month follow-up.

GLM repeated measures revealed that there was no significant main effect for time, for either perceived friendship quality $F(2,112)=0.34, p=0.75$ or life satisfaction $F(2$, $112)=0.78, p=0.43$ between the interpersonal gratitude intervention and control 
intervention. Also, there was no significant Condition $\times$ Time interactions for either perceived friendship quality, $F(2,112)=0.28, p=0.69$, or life satisfaction $F(2$, $112)=1.89, p=0.17$ across time (baseline, immediate post-test, follow-up) between the interpersonal gratitude intervention and the control intervention. As there were no statistically significant effects, mediation analysis was not explored.

In sum, Hypotheses 3 (a) and (b) were not supported, as the interpersonal gratitude intervention (vs. control) did not improve perceived friendship quality at immediate posttest or 1-month follow-up, and therefore no mediation analysis was conducted.

Hypothesis 4 There will be no differences in immediate post-test or 1-month follow-up outcomes between the interpersonal gratitude intervention and the traditional gratitude intervention.

GLM repeated measures revealed that participants in both the interpersonal gratitude intervention and the traditional gratitude intervention experienced improved life satisfaction over time, as indicated by a significant main effect of time, $F(2,110)=7.22$, $p=0.001, \eta^{2} \mathrm{p}=0.12$. Simple contrasts indicated a significant difference between baseline and immediate post-test $(F(1,55)=6.77, p=0.01)$ and baseline and follow-up $(F(1,55)=11.57, p=0.001)$. However, there was no significant Condition $\times$ Time interactions for life satisfaction $F(2,110)=0.41, p=0.66$ across time (baseline, immediate post-test, follow-up) between the interpersonal gratitude intervention and the traditional gratitude intervention. Similarly, GLM repeated measures revealed that participants in both the interpersonal gratitude intervention and the traditional gratitude intervention experienced change in perceived friendship quality over time, as indicated by a significant main effect of time, $F(2,110)=3.47, p=0.047, \eta^{2} \mathrm{p}=0.06$. However there were no significant Condition $\times$ Time interactions for perceived friendship quality, $F(2$, $110)=3.263, p=0.06$, across time (baseline, immediate post-test, follow-up) between the interpersonal gratitude intervention and the traditional gratitude intervention. As there were no statistically significant effects, mediation analysis was not explored.

In sum, in line with Hypothesis 4, there were no differences in immediate post-test or 1-month follow-up outcomes between the interpersonal gratitude intervention and the traditional gratitude intervention.

\section{Discussion}

Experiencing gratitude serves "as a very important thread in our social fabric" (Smith et al. 2014 , p. 11). Despite the application of gratitude interventions in practice to improve mental health, and importance of measuring the theorised active ingredients of interventions, research identifying the mechanism(s) responsible is extremely limited. Also, limited research has explored how gratitude journals can be adapted to enhance existing social relationships, which are consistently linked to favourable outcomes and necessary for high levels of life satisfaction (Diener and Seligman 2002). The current study attended to this by employing a rigorous longitudinal randomized controlled design, a guiding theory of change to support the proposed pathway, and directly testing for mediators. 


\subsection{Integration of Findings}

The study found, firstly, that completing a traditional gratitude journal that sought to elicit gratitude for daily life, improved perceived quality of friendships at immediate post-test and 1-month follow-up by changing levels of gratitude. This traditional gratitude journal also increased life satisfaction at 1-month follow-up, which was accounted for by increasing gratitude, and greater improvements in friendship and life satisfaction, relative to a control journal. Evidence that this traditional gratitude journal intervention operated through the mechanisms of increased gratitude is valuable given the dearth of studies examining the underlying pathways linking gratitude journals and life satisfaction. Given the popular portrayal of gratitude journals as an effective intervention (Wood et al. 2010; Davis et al. 2016), measuring the change mechanisms underlying their effect provides critical information for enhancing intervention design and outcomes, and developing and testing theory accounting for these causal processes (Frazier et al. 2004). These findings lend novel support to Fredrickson's broaden-and-build theory of positive emotions (1998, 2001, 2002, 2004b), which suggests that experiencing positive emotions have longterm adaptive benefits beyond the relatively transient nature of the psychophysiological reactions experienced during their acquisition. Importantly, in this case it was specifically the social emotion of gratitude, rather than general positive affect, that accounted for changes, as indicated by mediation analysis. Specifically, this effect of gratitude appears to have occurred via the building of perceived friendship quality and life satisfaction, which are enduring psycho-social resources. These results also lend support to the find-remindand-bind theory of gratitude that highlights its function in strengthening relationships with people with whom we engage and interact (Algoe 2012). Although theorized primarily on expressions of gratitude to a benefactor, it suggests that experiences of gratitude enhance that person's perception of the benefactor and relationship for which they are grateful, by reminding them of the positive qualities of that person and their relationship with them. Subsequently, this helps bind or strengthen their relationship. In this case, novel to the literature, actively recalling, recording, and appraising instances that made people grateful throughout the day served to promote feelings of gratitude which improved peoples' perceived friendship quality and subsequently improved their satisfaction with life.

Secondly, this study found that an interpersonal gratitude journal, that sought to elicit gratitude for interpersonal experiences and other people explicitly, did not differ significantly to either the control journal (which did not show any changes over time) or the traditional gratitude journal (which showed significant changes over time). This may be due to the fact that the interpersonal gratitude journal was more restrictive than the unmodified traditional gratitude journal and not potent enough, or too restrictive, to differ from the control journal. Suppressing autonomy through instruction in gratitude interventions has been shown to produce paradoxical effects (Kaczmarek et al. 2014). Further, the follow-up standard deviations for gratitude levels for the two gratitude conditions were quite different, suggesting that some participants became more grateful, but some became less grateful, and may account for the non-effect of the interpersonal intervention on life satisfaction, when compared to the other conditions. Perhaps some days participants simply did not have any social interactions that elicited gratitude, and requesting them to recall such events had adverse effects. This restricted range of reported gratitude events and lack of autonomy may explain why the interpersonal gratitude intervention seems to have been somewhat ineffective (Della Porta et al. 2012, as cited in Lyubomirsky and Layous 2013; Kaczmarek et al. 2014; Nelson et al. 2015). It is advocated that future researchers replicate 
and build on these findings and examine the role of gratitude in enhancing psychosocial and health outcomes using robust methodology.

\subsection{Limitations and Future Directions}

Although evidence of underlying pathways was found, this investigation is limited by its temporality and small sample size. More research is required to elucidate mediating factors underlying the success of gratitude journals and indeed other positive psychological interventions. In future studies, we recommend more intense treatment with longer followups to determine whether the traditional and/or interpersonal gratitude intervention indeed leads to longer term and sustained improvements in life satisfaction. Additionally, in the present study, multiple techniques were adopted to improve adherence, for example, researchers articulated the importance of completing the journal entries for the integrity of the results, participants were sent reminder text messages to complete their journal entries, participants were provided with the journals including clear instructions, which have been shown to enhance treat integrity (Perepletchikova and Kazdin 2005). Although there is no certainty that participants who chose not to return their journals adhered to instructions, all but one person returned after the intervention period and came into the lab and completed their immediate post-test follow-up. Many studies indicate that decreased treatment integrity is associated with a decreased probability of therapeutic change (Ehrhardt et al. 1996; Henggeler et al. 1997; Huey et al. 2000), and high levels of adherence are associated with an increased likelihood of expected changes (Perepletchikova and Kazdin 2005). The pre-emptive measures taken, the very low attrition rate, and the fact that significant effects on treatment outcome measures were found in the present research, dampens this concern. Very recent studies examining positive psychological interventions are beginning to utilize timestamps of entries where possible (Krejtz et al. 2016) or self-reported adherence, and measures of treatment integrity such as these are advocated in future research. Further, content analysis of journals in conjunction with statistical testing would help understand the participant experience, and shed more light on understanding findings. Nevertheless, there is sufficient evidence to recommend that gratitude journal interventions are further investigated as a technique to improve perceived evaluations of friendships and life satisfaction. Also, the current study, given the sample, operationalized social relationships in the contexts of adult friendships. Further studies are needed to understand which specific domains of social relationships are targeted by different interventions. This is important in order to optimally design and deliver positive psychology interventions to improve relationships, and ultimately peoples' happiness.

\section{Conclusion}

This research uniquely demonstrates evidence for key processes underlying how gratitude interventions exert effects on life satisfaction, through improving gratitude and perceived friendship quality. Given the dearth of well-designed and empirically tested interventions to sustain social relationships (Cohen and Janicki-Deverts 2009), and the recent call for interventions to strengthen social closeness (Kok and Fredrickson 2013) this line of investigation is both timely and needed. These findings add to the accumulating research advocating that gratitude be targeted for intervention and offers novel support for the psychosocial mechanisms of gratitude interventions. As little is known about the 
underlying dynamics of how positive psychological interventions operate, and given that gratitude journals are experiencing an unprecedented upsurge in academic and applied milieux, this study provides much needed information to aid in researcher's understandings, investigations and utilisation of gratitude interventions. Moreover, this was accomplished through employing rigorous longitudinal randomized controlled design. Actively appreciating the experiences we engage with in our daily lives appears to be a potent way for improving the quality of our social relationships, producing sustained improvements in psychological wellbeing and overall happiness.

\section{References}

Algoe, S. (2012). Find, remind, and bind: The functions of gratitude in everyday relationships. Social and Personality Psychology Compass, 6(6), 455-469. doi:10.1111/j.1751-9004.2012.00439.x.

Algoe, S. B., Fredrickson, B. L., \& Gable, S. L. (2013). The social functions of the emotion of gratitude via expression. Emotion, 13(4), 605-609. doi:10.1037/a0032701.

Algoe, S. B., Gable, S. L., \& Maisel, N. C. (2010). It's the little things: Everyday gratitude as a booster shot for romantic relationships. Personal Relationships, 17(2), 217-233.

Algoe, S. B., \& Haidt, J. (2009). Witnessing excellence in action: The 'other praising'emotions of elevation, gratitude, and admiration. The Journal of Positive Psychology, 4(2), 105-127. doi:10.1080/ 17439760802650519.

Algoe, S. B., Haidt, J., \& Gable, S. L. (2008). Beyond reciprocity: Gratitude and relationships in everyday life. Emotion, 8(3), 425-429. doi:10.1111/j.1751-9004.2012.00439.x.

Algoe, S. B., \& Stanton, A. L. (2012). Gratitude when it is needed most: Social functions of gratitude in women with metastatic breast cancer. Emotion, 12(1), 163-168. doi:10.1037/a0024024.

Bartlett, M. Y., Condon, P., Cruz, J., Baumann, J., \& Desteno, D. (2012). Gratitude: Prompting behaviours that build relationships. Cognition and Emotion, 26(1), 2-13. doi:10.1080/02699931.2011.561297.

Bertocci, P. A., \& Millard, R. M. (1963). Personality and the good: Psychological and ethical perspectives. New York: David McKay Co.

Cohen, S. (2004). Social relationships and health. American Psychologist, 59(8), 676-684. doi:10.1037/ 0003-066X.59.8.676.

Cohen, J., Cohen, P., West, S. G., \& Aiken, L. S. (2003). Applied multiple regression/correlation analysis for the behavioral sciences (3rd ed.). Mahwah, NJ: Lawrence Erlbaum Associates.

Cohen, S., Gottlieb, B. H., \& Underwood, L. G. (2000). Social relationships and health. New York: Oxford.

Cohen, S., \& Janicki-Deverts, D. (2009). Can we improve our physical health by altering our social networks? Perspectives on Psychological Science, 4(4), 375-378. doi:10.1111/j.1745-6924.2009. 01141.x.

Cyranowski, J. M., Zill, N., Bode, R., Butt, Z., Kelly, M. A., Pilkonis, P. A., et al. (2013). Assessing social support, companionship, and distress: National Institute of Health (NIH) Toolbox Adult Social Relationship Scales. Health Psychology, 32(3), 293-301. doi:10.1037/a0028586.

Davis, D. E., Choe, E., Meyers, J., Wade, N., Varjas, K., Gifford, A., et al. (2016). Thankful for the little things: A meta-analysis of gratitude interventions. Journal of Counseling Psychology, 63(1), 20-31.

Demir, M., \& Özdemir, M. (2010). Friendship, need satisfaction and happiness. Journal of Happiness Studies, 11(2), 243-259. doi:10.1007/s10902-009-9138-5.

Demır, M., \& Weitekamp, L. A. (2007). I am so happy' cause today I found my friend: Friendship and personality as predictors of happiness. Journal of Happiness Studies, 8(2), 181-211. doi:10.1007/ s10902-006-9012-7.

Diener, E., \& Chan, M. Y. (2011). Happy people live longer: Subjective well-being contributes to health and longevity. Applied Psychology: Health and Well-Being, 3(1), 1-43. doi:10.1111/j.1758-0854.2010. 01045.

Diener, E., Lucas, R. E., Oishi, S., \& Suh, E. M. (2002). Looking up and looking down: Weighting good and bad information in life satisfaction judgments. Personality and Social Psychology Bulletin, 28(4), 437-445.

Diener, E. D., Emmons, R. A., Larsen, R. J., \& Griffin, S. (1985). The satisfaction with life scale. Journal of Personality Assessment, 49(1), 71-75.

Diener, E., \& Seligman, M. E. (2002). Very happy people. Psychological Science (0956 7976), 13(1), 81-84. 
Duckworth, A. L., Steen, T. A., \& Seligman, M. E. (2005). Positive psychology in clinical practice. Annual Review of Clinical Psychology, 1, 629-651. doi:10.1146/annurev.clinpsy.1.102803.144154.

Ehrhardt, K. E., Barnett, D. W., Lentz, F. E., Jr., Stollar, S. A., \& Reifin, L. H. (1996). Innovative methodology in ecological consultation: Use of scripts to promote treatment acceptability and integrity. School Psychology Quarterly, 11(2), 149-168.

Emmons, R. A., \& McCullough, M. E. (2003). Counting blessings versus burdens: An experimental investigation of gratitude and subjective well-being in daily life. Journal of Personality and Social Psychology, 84(2), 377-389. doi:10.1037/00223514.84.2.377.

Emmons, R. A., \& Mishra, A. (2011). Why gratitude enhances well-being: What we know, what we need to know. In K. M. Sheldon, T. B. Kashdan, \& M. F. Steger (Eds.), Designing positive psychology: Taking stock and moving forward (pp. 248-262). New York, NY: Oxford University Press.

Emmons, R. A., \& Shelton, C. M. (2002). Gratitude and the science of positive psychology. Handbook of Positive Psychology, 18, 459-471.

Erdogan, B., Bauer, T. N., Truxillo, D. M., \& Mansfield, L. R. (2012). Whistle while you work: A review of the life satisfaction literature. Journal of Management, 38(4), 1038-1083.

Frazier, P. A., Tix, A. P., \& Barron, K. E. (2004). Testing moderator and mediator effects in counseling psychology research. Journal of Counseling Psychology, 51(1), 115-134. doi:10.1037/0022-0167.51.1. 115.

Fredrickson, B. L. (1998). What good are positive emotions? Review of General Psychology, 2(3), 300-319. doi:10.1037/1089-2680.2.3.300.

Fredrickson, B. L. (2001). The role of positive emotions in positive psychology: The broaden-and-build theory of positive emotions. American Psychologist, 56(3), 218-226. doi:10.1037/0003-066X.56.3. 218.

Fredrickson, B. L. (2002). Positive emotions. In C. R. Snyder \& S. J. Lopez (Eds.), Handbook of positive psychology (pp. 120-134). New York: Oxford University Press.

Fredrickson, B. L. (2004a). Gratitude, like other positive emotions, broadens and builds. In R. A. Emmons \& M. E. McCullough (Eds.), The psychology of gratitude (pp. 145-166). Oxford: Oxford University Press.

Fredrickson, B. L. (2004b). The broaden-and-build theory of positive emotions. Philosophical Transactions of the Royal Society B: Biological Sciences, 359(1449), 1367-1378. doi:10.1098/rstb.2004.1512.

Fredrickson, B. L. (2013). Positive emotions broaden and build. Advances in Experimental Social Psychology, 47, 1-53. doi:10.1016/B978-0-12-407236-7.00001-2.

Fredrickson, B. L., Cohn, M. A., Coffey, K. A., Pek, J., \& Finkel, S. M. (2008). Open hearts build lives: Positive emotions, induced through loving-kindness meditation, build consequential personal resources. Journal of Personality and Social Psychology, 95(5), 1045-1062. doi:10.1037/a0013262.

Garland, E. L., Fredrickson, B., Kring, A. M., Johnson, D. P., Meyer, P. S., \& Penn, D. L. (2010). Upward spirals of positive emotions counter downward spirals of negativity: Insights from the broaden-andbuild theory and affective neuroscience on the treatment of emotion dysfunctions and deficits in psychopathology. Clinical Psychology Review, 30(7), 849-864.

Grant, A. M., \& Gino, F. (2010). A little thanks goes a long way: Explaining why gratitude expressions motivate prosocial behavior. Journal of Personality and Social Psychology, 98(6), 946-955. doi:10. $1037 / \mathrm{a} 0017935$.

Hayes, A. F. (2009). Beyond Baron and Kenny: Statistical mediation analysis in the new millennium. Communication monographs, 76(4), 408-420. doi:10.1080/03637750903310360.

Hayes, A. F. (2013). An introduction to mediation, moderation, and conditional process analysis. New York: The Guilford Press.

Henggeler, S. W., Melton, G. B., Brondino, M. J., Scherer, D. G., \& Hanley, J. H. (1997). Multisystemic therapy with violent and chronic juvenile offenders and their families: The role of treatment fidelity in successful dissemination. Journal of Consulting and Clinical Psychology, 65(5), 821-833. doi:10. 1037/0022-006X.65.5.821.

Holt-Lunstad, J., Smith, T. B., \& Layton, J. B. (2010). Social relationships and mortality risk: A metaanalytic review. PLoS Medicine, 7(7), e1000316. doi:10.1371/journal.pmed.1000316.

Huey, S. J., Jr., Henggeler, S. W., Brondino, M. J., \& Pickrel, S. G. (2000). Mechanisms of change in multisystemic therapy: Reducing delinquent behavior through therapist adherence and improved family and peer functioning. Journal of Consulting and Clinical Psychology, 68(3), 451-467. doi:10. 1037/0022-006X.68.3.451.

Jenkins, J. M., \& Oatley, K. (1996). Emotional episodes and emotionality through the life span. In C. Magai \& S. H. McFadden (Eds.), Handbook of emotion, adult development, and aging (pp. 421-441). doi:10. 1016/B978-012464995-8/50024-8. 
Kaczmarek, L. D., Goodman, F. R., Drążkowski, D., Kashdan, T. B., Połatyńska, K., \& Komorek, J. (2014). Instructional support decreases desirability and initiation of a gratitude intervention. Personality and Individual Differences, 64, 89-93. doi:10.1016/j.paid.2014.02.022.

Katz, M. H. (2011). Multivariable analysis: A practical guide for clinicians and public health researchers. Cambridge: Cambridge University Press.

Killen, A., \& Macaskill, A. (2015). Using a gratitude intervention to enhance well-being in older adults. Journal of Happiness Studies, 16(4), 947-964. doi:10.1007/s10902-0149542-3.

Kok, B. E., Coffey, K. A., Cohn, M. A., Catalino, L. I., Vacharkulksemsuk, T., Algoe, S. B., et al. (2013). How positive emotions build physical health perceived positive social connections account for the upward spiral between positive emotions and vagal tone. Psychological Science, 24(7), 1123-1132. doi: $10.1177 / 0956797612470827$.

Kok, B. E., \& Fredrickson, B. L. (2013). Well-being begins with "We": The physical and mental health benefits of interventions that increase social closeness. In F. Huppert \& C. Cooper (Eds.), Wellbeing: A complete reference guide, interventions and policies to enhance wellbeing (Vol. 6, pp. 1-29). Oxford: Blackwell: John Wiley \& Sons.

Krejtz, I., Nezlek, J. B., Michnicka, A., Holas, P., \& Rusanowska, M. (2016). Counting one's blessings can reduce the impact of daily stress. Journal of Happiness Studies, 17(1), 25-39. doi:10.1007/s10902-0149578-4.

Krentzman, A. R., Mannella, K. A., Hassett, A. L., Barnett, N. P., Cranford, J. A., Brower, K. J., et al. (2015). Feasibility, acceptability, and impact of a web-based gratitude exercise among individuals in outpatient treatment for alcohol use disorder. The Journal of Positive Psychology, 10(6), 477-488. doi:10.1080/17439760.2015.1015158.

Lambert, N. M., \& Fincham, F. D. (2011). Expressing gratitude to a partner leads to more relationship maintenance behavior. Emotion, 11(1), 52-60. doi:10.1037/a0021557.

Loeys, T., Moerkerke, B., \& Vansteelandt, S. (2015). A cautionary note on the power of the test for the indirect effect in mediation analysis. Frontiers in Psychology, 5, 1549.

Lyubomirsky, S., \& Layous, K. (2013). How do simple positive activities increase well being? Current Directions in Psychological Science, 22(1), 57-62. doi:10.1177/0963721412469809.

McCullough, M. E., Emmons, R. A., \& Tsang, J. A. (2002). The grateful disposition: a conceptual and empirical topography. Journal of Personality and Social Psychology, 82(1), 112-127. doi:10.1037// 0022-3514.82.1.112.

McCullough, M. E., Kilpatrick, S. D., Emmons, R. A., \& Larson, D. B. (2001). Is gratitude a moral affect? Psychological Bulletin, 127(2), 249-266. doi:10.1037/00332909.127.2.249.

Michel, A., O'Shea, D., \& Hoppe, A. (2015). Designing and evaluating resource-oriented interventions to enhance employee well-being and health. Journal of Occupational and Organizational Psychology, 88(3), 459-463. doi:10.1111/joop.12131.

Myers, D. G. (2000). The funds, friends, and faith of happy people. American Psychologist, 55, 56-67. doi:10.1037/0003-066X.55.1.56.

Nelson, S. K., Della Porta, M. D., Jacobs Bao, K., Lee, H. C., Choi, I., \& Lyubomirsky, S. (2015). 'It's up to you': Experimentally manipulated autonomy support for prosocial behavior improves well-being in two cultures over six weeks. The Journal of Positive Psychology, 10(5), 463-476. doi:10.1080/ 17439760.2014.983959.

O'Connell, B. H., O'Shea, D., \& Gallagher, S. (2016). Enhancing social relationships through positive psychology activities: A randomised controlled trial. The Journal of Positive Psychology, 11(2), 149-162. doi:10.1080/17439760.2015.1037860.

O'Shea, D., O'Connell, B. H., \& Gallagher, S. (2015). Randomized controlled trials in WOHP interventions: A review and guidelines for use. Applied Psychology: An International Review, 65(2), 190-222. doi:10.1111/apps.12053.

Pavot, W., \& Diener, E. (1993). Review of the satisfaction with life scale. Psychological Assessment, 5(2), 164-172. doi:10.1007/978-90-481-2354-4_5.

Pearce, M. J., Koenig, H. G., Robins, C. J., Daher, N., Shaw, S. F., Nelson, B., et al. (2016). Effects of religious versus conventional cognitive-behavioral therapy on gratitude in major depression and chronic medical illness: A randomized clinical trial. Journal of Spirituality in Mental Health, 2(3), 202-215. doi:10.1037/scp0000076.

Perepletchikova, F., \& Kazdin, A. E. (2005). Treatment integrity and therapeutic change: Issues and research recommendations. Clinical Psychology: Science and Practice, 12(4), 365-383. doi:10.1093/ clipsy.bpi045.

Preacher, K. J., \& Hayes, A. F. (2004). SPSS and SAS procedures for estimating indirect effects in simple mediation models. Behavior Research Methods, Instruments, \& Computers, 36(4), 717-731. doi:10. 3758/bf03206553. 
Preacher, K. J., \& Hayes, A. F. (2008). Asymptotic and resampling strategies for assessing and comparing indirect effects in multiple mediator models. Behavior Research Methods, 40(3), 879-891. doi:10. 3758/BRM.40.3.879.

Preacher, K. J., Rucker, D. D., \& Hayes, A. F. (2007). Addressing moderated mediation hypotheses: Theory, methods, and prescriptions. Multivariate Behavioural Research, 42(1), 185-227. doi:10.1080/ 00273170701341316.

Rash, J. A., Matsuba, M. K., \& Prkachin, K. M. (2011). Gratitude and well-being: Who benefits the most from a gratitude intervention? Applied Psychology: Health and Well-Being, 3(3), 350-369. doi:10. $1111 /$ j.1758-0854.2011.01058.

Reis, H. T. (2001). Relationship experiences and emotional well-being. In C. D. Ryff \& B. H. Singer (Eds.), Emotion, social relationships, and health (pp. 57-86). New York: Oxford University Press.

Rucker, D. D., Preacher, K. J., Tormala, Z. L., \& Petty, R. E. (2011). Mediation analysis in social psychology: Current practices and new recommendations. Social and Personality Psychology Compass, 5(6), 359-371. doi:10.1111/j.17519004.2011.00355.x.

Schulz, K. F., Altman, D. G., \& Moher, D. (2010). CONSORT 2010 statement: Updated guidelines for reporting parallel group randomized trials. Annals of Internal Medicine, 152, 726-732. doi:10.7326/ 0003-4819-152-11-201006010-00232.

Seligman, M. E., Rashid, T., \& Parks, A. C. (2006). Positive psychotherapy. American Psychologist, 61(8), 774-788. doi:10.1037/0003-066X.61.8.774.

Seligman, M. E., Steen, T. A., Park, N., \& Peterson, C. (2005). Positive psychology progress: Empirical validation of interventions. American Psychologist, 60(5), 410.

Sheldon, K. M., \& Lyubomirsky, S. (2006). How to increase and sustain positive emotion: The effects of expressing gratitude and visualizing best possible selves. The Journal of Positive Psychology, 1(2), 73-82. doi:10.1080/17439760500510676.

Smith, C. A., Tong, E. M., \& Ellsworth, P. C. (2014). The differentiation of positive emotional experience as viewed through the lens of appraisal theory. Handbook of positive emotions (pp. 11-27). New York: Guilford.

Teixeira, P. J., Silva, M. N., Coutinho, S. R., Palmeira, A. L., Mata, J., Vieira, P. N., et al. (2010). Mediators of weight loss and weight loss maintenance in middle-aged women. Obesity, 18(4), 725-735. doi:10. 1038/oby.2009.281.

Toepfer, S. M., Cichy, K., \& Peters, P. (2012). Letters of gratitude: Further evidence for author benefits. Journal of Happiness Studies, 13(1), 187-201. doi:10.1007/s10902011-9257-7.

Tsang, J. A. (2006). BRIEF REPORT gratitude and prosocial behaviour: An experimental test of gratitude. Cognition and Emotion, 20(1), 138-148. doi:10.1080/02699930500172341.

Vandervoort, D. (1999). Quality of social support in mental and physical health. Current Psychology, 18(2), 205-221. doi:10.1007/s12144-999-1029-8.

Watkins, P. C., Uhder, J., \& Pichinevskiy, S. (2015). Grateful recounting enhances subjective well-being: The importance of grateful processing. The Journal of Positive Psychology, 10(2), 91-98. doi:10.1080/ 17439760.2014.927909.

Watkins, P. C., Woodward, K., Stone, T., \& Kolts, R. L. (2003). Gratitude and happiness: Development of a measure of gratitude, and relationships with subjective well-being. Social Behavior and Personality: An International Journal, 31(5), 431-451. doi:10.13072/midss.100.

Waugh, C. E., \& Fredrickson, B. L. (2006). Nice to know you: Positive emotions, self-other overlap, and complex understanding in the formation of a new relationship. The Journal of Positive Psychology, 1(2), 93-106. doi:10.1080/17439760500510569.

Wood, A. M., Froh, J. J., \& Geraghty, A. W. (2010). Gratitude and well-being: A review and theoretical integration. Clinical Psychology Review, 30(7), 890-905. doi:10.1016/j.cpr.2010.03.005.

Wood, A. M., Joseph, S., \& Maltby, J. (2008). Gratitude uniquely predicts satisfaction with life: Incremental validity above the domains and facets of the five factor model. Personality and Individual Differences, 45(1), 49-54. doi:10.1016/j.paid.2008.02.019.

Wood, A. M., Joseph, S., \& Maltby, J. (2009). Gratitude predicts psychological well-being above the big five facets. Personality and Individual Differences, 46(4), 443-447. doi:10.1016/j.paid.2008.11.012. 